\title{
El sueño y la muerte en Nostalgia de la muerte, de Xavier Villaurrutia, o de cómo definirse por la indefinición
}

Adriana Irais Dorantes Moreno Universidad de Guanajuato

\section{Resumen}

El tema central de análisis, concerniente a Nostalgia de la muerte, del poeta mexicano Xavier Villaurrutia, es la unión entre el sueño y la muerte. Su poesía se sitúa en escenarios oscuros y oníricos en donde el poeta experimenta una constante imposibilidad de identificación de sí mismo y de los otros. Sueño y muerte, elementos con antecedentes en el barroco y el romanticismo, son retomados en una propuesta que más que exaltar a la muerte, busca una reafirmación de la vida.

Palabras clave: Villaurrutia, sueño, muerte, otredad, vida.

\section{Abstract}

The central theme of this analysis concerning Nostalgia de la muerte, by Mexican poet Xavier Villaurrutia, is the union between death and dream. His poetry takes place in dark and oneiric scenarios where the poet experiences a constant impossibility to identify himself and others. Death and dream, both elements with strong antecedents in Baroque and Romanticism are reworked in a proposal wherein, rather than exalting death, function as a reaffirmation of life.

Keywords: Villaurrutia, dream, death, otherness, life. 
$\mathrm{H}$ ermanos gemelos, como los llamara Homero, sueño y muerte han estado en relación íntima en la literatura, incluso forman parte del tópico Vita somnium utilizado por Calderón de la Barca, en La vida es sueño, para ilustrar el carácter onírico de toda la existencia. También lo escribió Quevedo: "El sueño, que es imagen de la muerte" (Quevedo, 1986: 55), morir como despertar al sueño que es la vida. De esta unión se desprende el análisis y comentario que se presenta, con la finalidad de exponer algunas características y recurrencias de dicho binomio en Nostalgia de la muerte, así como su resonancia en la concepción de la muerte reafirmando la vida.

El tópico de la muerte fue muy apreciado por los Contemporáneos; muy cerca de la publicación de la obra cumbre de Villaurrutia, en 1938, vieron la luz Muerte sin fin (1939), de José Gorostiza, y Muerte de cielo azul (1937), de Bernardo Ortiz de Montellano. En palabras de Villaurrutia, esto responde a que la relación íntima que se establece con la muerte, no es para verla como extranjera y temible sino como propia y cotidiana, "acaso porque en momentos como los que ahora vivimos, la muerte es lo único que no le pueden quitar al hombre; le pueden quitar la fortuna, la vida, pero la muerte ¿quién me la va a quitar?” (Villaurrutia, 1966a: 18). Esta muerte ya nace dentro del poeta, ya es algo tan conocido por el hombre que incluso crece con ella.

En opinión de Octavio Paz, la predilección por dicho tema dentro del llamado "Grupo sin grupo" responde a una cuestión de desencanto y de escepticismo social, pues al haber vivido las matanzas revolucionarias seguidas de la corrupción instaurada por los mismos grupos de poder, era una generación que no pudo hacerse ningún tipo de ilusiones como lo hicieran sus antecesores y por eso "se aislaron en un mundo privado, poblado por los fantasmas del erotismo, el sueño y la muerte. Un mundo regido por la palabra ausencia” (Paz, 1978: 22). En el caso de Villaurrutia, no sólo 
el desencanto, sino la influencia del surrealismo será fundamental para su poesía pues, de hecho, "la reflexión y la crítica en torno al surrealismo las empezó a desarrollar Villaurrutia a partir de 1930 en numerosos artículos de prensa, reseńas, comentarios, ensayos o conferencias" (Monge, 2001: 283). Así, desde sus primeras manifestaciones artísticas, el autor mostraba predilección por uno de los aspectos más fascinantes de este movimiento de vanguardia: el sueño. En Monólogo para una noche de insomnio, escrito cuando Villaurrutia tenía sólo 22 años, se aprecian un par de párrafos reveladores:

Acaso, acaso, frente a tan desoladas perspectivas solamente aparezca con el prestigio de lo desconocido, con vaguedad imprecisa apenas enunciada el culto metódico, científico y regular del sueño.

Vida perfecta la que el sueño proporciona. Vida que consigue, a menudo, el equilibrio entre el descanso del cuerpo y del alma, sosiego del espíritu, inercia del organismo, euforia y ataraxia, ideal griego. Vida también libre y amplia; accidentada y diversa como la esencia del hombre. Vida que nos ofrece tan múltiples aspectos que hasta al más exigente curioso deja complacido (1966b: 604).

Los escenarios en que Villaurrutia inscribe su obra no se separan del sueño; es posible rastrear el origen de esta predilección en sus propias filiaciones. Villaurrutia se declara hijo de la vanguardia europea, de los simbolistas y románticos, más que de la generación hispana que literariamente lo precede: "Si ha habido una escuela poética de quien me sienta totalmente opuesto y extraño es del Modernismo. Para mí no tiene sentido alguno la poesía que es puro juego exterior o encanto a los sentidos" (1966a: 18). El gusto de Villaurrutia está fuertemente marcado por lo onírico, el sueño de vida que encuentra en la poesía romántica; por ejemplo, en Aurelia, de Nerval. Esta obra es "en dos sentidos, una obra de sueńo; en primer lugar porque el sueño constituye en ella, con la vigilia, un 
todo indisoluble y continuo, y en segundo lugar porque describe al mismo tiempo la conquista de la salvación y la lenta adquisición de los dones del sueño" (Béguin, 1992: 437-438). En palabras de Villaurrutia, "vigilia y sueño se comunican en el texto poético de Gérard de Nerval al punto que las fronteras entre ambos mundos no sólo se han borrado ya sino que son innecesarias" (1966b: 896). Villaurrutia halla, de hecho, una manera de unir armónicamente la vida y el sueño, constante muy marcada en su obra.

Remitiéndonos a sus gustos literarios personales y a quienes considera sus "padres poéticos”, la visión del sueño en Villaurrutia recuerda incluso la sensibilidad romántica en la que el artista "apela al mundo rico e informe de los sueños, a la fértil turbulencia que, todavía no cercenada por el hombre, aloja los flujos más verdaderos y espontáneos de la subjetividad. Y esta turbulencia todavía no domada, dolorosa pero fecunda, es el Inconsciente" (Argullol, 2006: 64), y donde esa fuerza subjetiva, es también la productora de nuevas realidades que marcadas por el sueño resultarán en Villaurrutia terrenos predilectos y fértiles, como veremos más adelante.

El poeta romántico está consciente de que la poesía tiene su origen en lugares alejados de la consciencia, escondidos en profundidades interiores y oscuras. El poeta asiste a la conformación del poema y contempla con la mirada su formación con ayuda de la imaginación creadora. Así "el empleo que el poeta romántico hace del sueño, como modelo o como fuente de inspiración, se distingue por eso del empleo que hacían otros poetas, para quienes el sueño no pasaba de ser un artificio técnico, o bien un simple ornamento de su obra” (Béguin, 1992: 199). Por otro lado, J. G. Herder entiende el sueño como un espacio donde el espíritu es soberano y se libera de las contingencias, este poeta admira en el sueño: "su ligereza, que contraste con la pesadez de la realidad, su atmósfera de país de hadas y sobre todo la revelación de los secretos 
del alma" (Béguin, 1992: 201). Muy semejante es la importancia que da Villaurrutia al sueńo, en tanto que para él en los terrenos de lo onírico se genera no sólo una inspiración sino una forma de vida y de poesía.

Nostalgia de la muerte está dividida en tres partes: "Nocturnos", "Otros nocturnos" y "Nostalgias". Alí Chumacero comentó que Nostalgia de la muerte es el poemario más logrado de Villaurrutia. De manera muy general, podemos decir que la mayoría de los poemas presentan a un yo lírico en constante secreto, con dudas, situado en el abandono, en escisión y fragmento, en búsqueda constante del otro y de sí mismo, muchas veces sin concretar el hallazgo. Los escenarios son antitéticos: vigilia y sueño se contraponen, así como muerte y vida, entre otros, y casi todos los poemas se inscriben en el mundo nocturno y cerrado. "Nocturno miedo" es un poema que, al igual que otros de este volumen, inserta la recurrencia de Villaurrutia por inscribir su yo lírico dentro de un mundo onírico y también anuncia, dentro de la nebulosidad propia del sueño, su concepción de la otredad.

El primer verso de "Nocturno miedo" se inscribe en la noche, lugar de oscuridad física y también del interior del poeta: "Todo en la noche vive una duda secreta” (Villaurrutia, 1966b: 45). ${ }^{9} \mathrm{El}$ poeta se instala en un no-decir, en un intersticio, con el escenario nocturno como espacio de su secreto, mismo que ofrece la posibilidad de realizar acciones:

Entonces, con el paso de un dormido despierto, sin rumbo y sin objeto nos echamos a andar.

La noche vierte sobre nosotros su misterio, y algo nos dice que morir es despertar. (vv. 9-12)

${ }^{9}$ Todas las referencias a los poemas de Villaurrutia corresponden a esta edición. 
La lucha entre estar despierto y estar dormido sucede en tensión; un verso antes se lee: "en la gruta del sueńo la misma luz nocturna nos vuelve a desvelar" (vv. 7-8). En los versos se advierten dos posibles significados de "desvelar": "estar sin dormir" y "descubrir"; la luz, que es nocturna, contribuye a la tensión, pues se trata de la pugna por dejar ver a la luz, y por esconder con la noche, al mismo tiempo.

Mucho se repite la tensión en la obra de Villaurrutia, reforzada con el uso de antítesis; Octavio Paz resume el tema verdadero de Nostalgia de la muerte como un conflicto, pues se trata de una poesía "habitada por una doble oposición: el sueño, la vigilia, la conciencia y el delirio" (Paz, 1978: 58). El choque de conceptos, las estatuas despiertas, los ojos cerrados que ven, los abiertos que no ven, son algunas representaciones de ese conflicto.

Si bien la noche es, como vimos en la doble tensión de "ver" y "esconder", un escenario de lo inconcreto, también es un elemento cómplice, pues bajo su oscuridad permite el encuentro con el otro. Incluso la sombra puede transformarse en luz. A Villaurrutia el descubrimiento de este tono de poesía no le llegó fácilmente pero al toparse con el tópico nocturno lo pudo entender: "Hubo un día en que me di cuenta de que entendía particularmente el clima de la noche, el del Nocturno, que era como la clave para mi poesía" (1966a: 19).

Por eso Villaurrutia invoca frecuentemente a la noche; Ramón Xirau abstrae el espacio nocturno como una manera de escindirse voluntariamente de las cosas y apunta que "en los Nocturnos el poeta ha logrado poner, en el título mismo del libro, una muralla de sombra entre la realidad y el espíritu. En la noche las cosas dejan de existir y se siente palpitar interna conciencia aislada del mundo" (2004: 162). Villaurrutia, más que buscar una separación, pugna por un encuentro muy específico con partes de su propio ser. Para el poeta la noche es cómplice, además tiene las caracterís- 
ticas necesarias para que le funcione como guarida y elemento que proporciona la idea de cuidado y espacio de seguridad: "Porque la noche arrastra en su baja marea / memorias angustiosas, temores congelados" (v. 53) y también es elemento que detiene el tiempo para preservar instantes, como lo enuncia el poema "Cuando la tarde":

Cuando la noche de humo, de polvo y de ceniza

Envuelve la ciudad, los hombres quedan

Suspensos un instante,

Porque ha nacido en ellos, con la noche, el deseo. (vv. 23-26)

Es ya sabido que uno de los elementos predilectos por los poetas románticos —a quienes Villaurrutia leyó ávidamente y realizó crítica sobre su obra—, es la noche; pero más que sólo un elemento paisajístico, Villaurrutia encuentra en ella el momento y el espacio predilecto de la completitud, lugar donde el deseo de la muerte es un deseo amoroso: "Un día todo será cuerpo, un cuerpo único. Y la pareja bienaventurada ha de bañarse en esa sangre celeste" (Paz: $1978,58)$. En este poema, Villaurrutia se ocupa del instante justo en que fenece la tarde para así enfatizar la gloriosa llegada de la noche:

Cuando la tarde al fin, ha recogido

el último destello de luz, la última nube,

el reflejo olvidado y el ruido ininterrumpido,

la noche surge silenciosamente. (vv. 8-11)

De la misma manera, Novalis en Los Himnos a la noche había tomado algunos versos para centrar la atención en el día, antes de dar paso al motivo real de su poesía: 
¿Ha de volver siempre la mañana?

¿Jamás terminará el señorío de lo terrenal?

Desdichada actividad estorba

el celestial vuelo de la noche. (Novalis, 1985: 33)

La noche cómplice tiene un compañero. Villaurrutia lo hace evidente en el último verso de "Nocturno miedo", que tiene un antecedente en la rima LXIX de Gustavo Adolfo Bécquer cuyo último verso es: “¡despertar es morir!” (1976: 60). El sueño, igualmente posibilita el encuentro con el otro y en la otredad existe un cambio de perspectiva. El sueńo, según Argullol es "una necesidad y un poder" (Argullol, 2006: 65). Notemos que es sólo con el paso del "dormido despierto" que el poeta se mueve también; es decir, hay un paso del estatismo al movimiento. Si el mundo onírico ofrece mayores satisfacciones vitales que el mundo real, se puede seguir que el poeta intuya, igual que Bécquer, que despertar es morir. Además, el sueño permite una nueva descripción del mundo, es una verdadera relación con la poesía, pues para Villaurrutia "el tema del poeta es el sueño..., pero es muy difícil abordarlo" (Paz, 1978: 56).

En el mismo poema, Villaurrutia, sumergido en la duda secreta, es consecuente con el carácter indefinido de la otredad; es decir, no es un hombre propiamente dicho, recordemos, es un "dormido despierto". La antítesis remite a la indefinición, la cual se trata muchas veces de un punto "entre" dos conceptos definidos y que resulta bastante abstracto, como lo es también el otro. El sonámbulo no es ninguna de las dos cosas, ni despierto, ni dormido. Para continuar con la idea de lo "entre", el siguiente verso plantea una pregunta fundamental:

¿Y quién entre las sombras de una calle desierta, en el muro, lívido espejo de soledad, no se ha visto pasar o venir a su encuentro y no ha sentido miedo, angustia, duda mortal? (vv. 13-16) 
Es de notar el adverbio de lugar: "entre", y la elección de las sombras de una calle desierta que conforman una indefinición. Por ejemplo (y esto es algo que se repite), si Villaurrutia quiere hablar de la palabra y el silencio, prefiere utilizar un punto medio abstracto, quizá el murmullo, el eco, o el "acento": "y ni siquiera el acento de una voz indefinible" (v. 5). Aquí se refiere a un ser, marcado por el "quién", pero es imposible saber la identidad y tampoco su constitución física, bien puede ser el otro, o uno mismo, pero como sea, no es un hombre sino la sombra. Sin embargo, ¿̇cómo podría haber sombra si no hay un hombre que la proyecte? Habría que tomar en cuenta un juego más de lo indefinido: lo desierto no está realmente desierto, pues tiene sombras, y conectando con los versos anteriores, lo secreto no es realmente secreto pues siempre se logra develar algo.

Antes mencioné que Villaurrutia se vale de las antítesis constantemente y pareciera que en la mitad de un concepto y otro, el poeta buscara siempre mostrar algo más; no es gratuito el epígrafe del poeta inglés Michael Drayton, el cual sugiere una imagen indefinida, imposible y al mismo tiempo totalmente contradictoria: "burned in a sea of ice, and drowned amidst a fire" (Villaurrutia, 1966b: 44). Recurrentes resultan ya las oposiciones: soledad / compañía, silencio / ruido, sueño / vigilia, tiempo / eternidad, nada / todo. No es que el poeta busque sólo contraponer o bien trasmutar esto con aquello, sino que busca el lugar que se inserta entre dichos conceptos y justo dicho lugar indefinido es uno de sus preferidos. Apunta Paz la importancia del momento de tránsito, el instante en que algo deja de ser una cosa y se convierte en otra, por ejemplo, cuando "la nieve comienza a obscurecerse pero sin ser sombra todavía" (Paz, 1978: 84). Mucho de eso se observa en Villaurrutia, un entre que no puede asirse ni expresarse pero que, paradójicamente, es el lugar más seguro. Siguiendo a Paz, el entre 
"no tiene cuerpo ni sustancia. Su reino es el pueblo fantasmal de las antinomias y las paradojas. El entre dura lo que dura el relámpago" (Paz, 1978: 85). Pero el "entre" inexpresable puede tratar de enunciarse mediante un intento de comparación, un estado del "como"; así lo hace en "Cementerio en la nieve":

Y ya no queda sino la nieve sobre la nieve como la mano sobre sí misma eternamente posada. Los pájaros prefieren atravesar el cielo, herir los invisibles corredores del aire para dejar sola la nieve, que es como dejarla intacta, que es como dejarla nieve. (vv. 5-11)

Estos versos anuncian la falta de comprensión frente a elementos que superan al ser humano; Villaurrutia fracasa en la imagen de la mano posada sobre sí misma pues tal no equivale a la quietud de la nieve, sólo puede decir que es "como" tal quietud, pero no igual. Tampoco quiere que los pájaros toquen la nieve pero sabe que no hay manera de dejarla intacta, esto porque quizá ahora ya ha hablado de ella y eso la ha cambiado. ${ }^{10}$

Así, la preposición "entre" y el adverbio modal "como" han de resolverse en el silencio, en lo que se sugiere atrapado entre conceptos pero no se pueden definir: “¿Qué nombre dar a la blancura

${ }^{10}$ El tema de la palabra es también un asunto de gran inquietud para Villaurrutia; nombrar y designar como un equivalente a la realidad, al igual que el silencio como alternativa, aparecen en algunos poemas de Nostalgia de la muerte e incluso en algunos de sus primeros poemas. Dicho conflicto se puede plantear precisamente desde la decisión léxica de los lugares "entre" y "como" que regresan en varios poemas; sin embargo, me parece que es un tema de filosofía del lenguaje, que no podría analizarse profundamente en la brevedad de este ensayo. 
sobre lo blanco?” (v. 2) pregunta el poeta, quien al final prefiere no indagar siquiera en cómo mencionarlo.

La indefinición de Villaurrutia sucede también al enfrentarse al otro. El "Nocturno de la estatua" muestra una carrera sin hallazgo, una búsqueda sin logro. El yo lírico está tratando de asir pero inevitablemente se topa con paredes de imposibilidades. Este camino errático es lo que Xirau llama "desrealización radical", pues "el poeta pasa a la ingravidez de los sonidos; y el sonido mismo se le convierte en eco, fantasma desdibujado de sí mismo" (Xirau, 2004: 163). En efecto, el poeta busca a la estatua y desea tocarla, pero esta actividad está condenada a no consumarse desde el principio. El resultado de su búsqueda es incompleto, en parte por la influencia del surrealismo, en parte por la imposibilidad, a priori, de llegar a establecer contacto con un otro:

Correr hacia la estatua y encontrar sólo el grito querer tocar el grito y sólo hallar el eco, querer asir el eco y encontrar sólo el muro y correr hacia el muro y tocar un espejo (vv. 5-6)

El poeta recorre distancias y desea de tocar, pero se enfrenta a puertas sin salida; es decir, sus hallazgos, tan mínimos, son etéreos: el grito y el eco. Mas él lo sabe desde el principio, no sufre realmente la imposibilidad y en este poema se sitúa de nueva cuenta en el espacio intermedio al reafirmar que el contacto no es viable. Para Villaurrutia el "entre" no es un destino trágico sino la decisión que toma como su verdad. Después, aunque ya materiales, no lo llevan a ningún lugar: el muro y el espejo. Esta persecución es discontinua y fragmentada, propia del espacio onírico: "Soñar, soñar la noche, la calle, la escalera" (v. 1) y contiene las peculiaridades inmateriales y contrapuestas de los sueños.

Al hacer un leve contacto: "jugar con las fichas de sus dedos" (v. 11), el poeta se reconoce a sí mismo, primero en el espejo que 
corta en seco su búsqueda así como en la caricia que le hace a la estatua "como a una hermana imprevista" (v. 10). El poeta, hacia el final, entra en un sueño dentro del sueño, pues la estatua, en la que él mismo puede reconocerse, rompe de lleno el movimiento en el último verso: "hasta oírla decir: 'estoy muerta de sueño" (v. 13). De este modo se evidencia la indefinición del otro. El poeta desea la otredad pero lo único que obtiene es un reflejo de sí mismo, igualmente indefinido, difuso, producto de un sueño. El poeta se ha reconocido muerto frente a su propio reflejo "hallar en el espejo la estatua asesinada" (v. 7) y de esta manera no se puede decir que esté vivo ni realmente muerto pues aún puede enunciar palabras. De nueva cuenta se ha posicionado en lo indefinido, en el lugar intermedio donde no se puede terminar de ser, de ser o de nombrar.

La falta de definición de sí mismo, sea o no ayudado del plano onírico, regresa en otros poemas; "Nocturno solo" enuncia, por ejemplo, la alienación del ser a causa de la falta del otro. Cito el poema completo a continuación:
Soledad, aburrimiento, vano silencio profundo, líquida sombra en que me hundo, vacío del pensamiento. Y ni siquiera el acento de una voz indefinible que llegue hasta el imposible rincón de un mar infinito a iluminar con su grito este naufragio invisible.

Éste es uno de los poemas que, en mi opinión, mejor abstraen la indeterminación del yo. Está enunciado desde la soledad y el silencio, el yo lírico se muestra apartado y hundiéndose; además no posee pensamiento y sin pensamiento no posee existencia ni 
mucho menos conformación de identidad. El yo lírico busca el acento siquiera de una otredad que con su voz "indefinible" será capaz de salvarlo de su lugar abstracto, que además es "imposible" "infinito" e "invisible".

El hundimiento del poeta apela a un viaje dentro de sí mismo, en la búsqueda por un reconocimiento personal. A la manera romántica, Villaurrutia experimenta un viaje hacia el yo, para conocer las profundidades del espíritu propio, donde quizá podría ayudar a definirse a sí mismo y ser rescatado del abismo, de su "naufragio invisible".

Otra respuesta frente a la indefinición aparece en el miedo que es la conclusión en sí de "Nocturno miedo". El poeta establece un sentimiento paradójico: teme estar vacío y también teme hallarse ocupado por otro que le cancele su identidad. El último verso es fundamental pues glosa el conflicto de la definición del ser, al tiempo que cierra la idea de la vida como sueńo y el despertar como muerte para crear una veta de lectura sobre la existencia y el reconocimiento de uno mismo: "y la duda de ser o no ser en realidad" (v. 20).

¿Dormir o despertar? Se pregunta Villaurrutia constantemente, mas el caso es que no elige ninguna opción, sino que regresa al punto intermedio. El sonambulismo definido por el "dormido despierto" es ese espacio onírico-consciente que permite el reconocimiento de uno mismo y también ahí existe la posibilidad de contacto con el otro. El tema del sueño lo ha trabajado el poeta desde antes de Nostalgia de la muerte, y no sólo en la poesía; en Dama de Corazones (1928), la única novela de Villaurrutia, retoma el tópico del sueño como una vía para ser plenamente. Cuando el narrador describe ciertas actitudes de la protagonista, Aurora, dice: "apenas si en el sueńo, vertiginosamente, vivimos en intensidad, en sólo un instante, lo inesperado, lo trágico, la felicidad, el azar. Para ella, todo lo que no es sueño no es vida. Sonríe y añade que la más per- 
fecta de nuestras costumbres en nada difiere de la muerte. Dormir sin soñar ¿qué otra cosa es sino morir?” (Villaurrutia, 1966b: 594).

El binomio no se desvanece, muerte y sueño siguen de la mano fuertemente. Sobre esa línea y dentro de la necesidad de otredad, basten un par de ejemplos más, en "Nocturno sueño" el poeta describe la entrada al mundo onírico mediante la prosopopeya: "abría las salas / profundas el sueño” (vv. 1-2) seguido de más sugerencias que enfatizan la transición hacia un plano onírico, disgregado, tales como la inversión de planos "el cielo en el suelo / como en un espejo" (vv. 12-13) o la separación de su cuerpo: "mi mano acerada / encontró mi espalda" (vv. 28-29). La escisión de sí mismo es para crear un desdoblamiento, ya antes sugerido por el espejo, y así poderse encontrar grácilmente con su otro perdido y decir: "Lo tomé en los brazos / lo llevé a mi lecho" (vv. 34-35), donde el "lo" se refiere a su propio cuerpo.

El otro, ausente, también podrá ser encontrado en el mundo onírico, ahí, solamente ahí, donde el contacto con el otro, como sucedió con el toque de la estatua, es posible de realizar, pues

la búsqueda de esta "otra realidad", presenciada en los sueños y por los procedimientos de la irracionalidad, está relacionada no únicamente con el mundo de lo oculto, sino también con el mundo del otro ser (de la "otredad"). Y a partir de ello con la complejidad de la comunicación amorosa (Monge, 2001: 290).

Villaurrutia abre Nostalgia de la muerte con "Nocturno", un poema que contiene los tópicos que tratará en todo el libro y que funciona también como una declaración de principios poéticos, pues contiene los temas recurrentes y las obsesiones así como su manera de resolverlas. El poeta enuncia todo lo que - en orden: la noche, la sombra, el silencio, el deseo y el sueńo- le posibilita los encuentros, la identificación, la completud. Está presente, sin duda, el sueño como escenario predilecto, cuidado por la noche sin olvidar 
a la muerte como un motivo de deseo y como algo propio. Vale la pena resaltar un par de estrofas de dicho poema:

\author{
Todo lo que el deseo \\ unta en mis labios: \\ la dulzura soñada \\ de un contacto, \\ el sabido sabor \\ de la saliva. \\ Y todo lo que el sueño \\ hace palpable: \\ la boca de una herida, \\ la forma de una entraña, \\ la fiebre de una manoque se atreve.
}

¡Todo!

circula en cada rama

del árbol de mis venas,

acaricia mis muslos,

inunda mis oídos,

vive en mis ojos muertos,

muere en mis labios duros. (vv. 20-38)

La prosopopeya del deseo le impone acciones, lo toca y le permite llegar al contacto y sentir la saliva. El poeta busca el contacto, la otredad; afirma que el mundo onírico hace perceptible las cosas, no ya el grito de la estatua de la que sólo se toca el eco sino que es posible hallar a un otro que "se atreve", un espacio donde el cuerpo propio no se fragmenta para perderse sino que se afirma en cada parte para vivir y al mismo tiempo morir la muerte conocida y amiga sobre la que el poeta ya ha hecho declaraciones. La última estrofa es el encuentro de sí mismo pues ya es capaz de sentir su corporalidad, y declara que el resto del poemario presentará el con- 
flicto del ser a través de la antítesis vida / muerte y de sus propias percepciones al respecto.

No es gratuito el título que Villaurrutia eligió para la obra; la figura de la muerte es, sin duda, fundamental, ya sea como arquetipo, como forma o como persona, y el poeta la retrata con diferentes características; en "Nocturno en que habla la muerte", es una representación humana, que se pone casi de igual a igual con el poeta, pero siempre con un conocimiento mayor. Esta muerte es una presencia que declaradamente está ahí todo el tiempo, sin que pueda ser eludida; cuando habla, dice:

Te he seguido como la sombra que no es posible dejar así nomás en casa como un poco de aire cálido e invisible mezclado al aire puro que respiras; como el recuerdo de lo que más quieres. (vv. 9-13)

La muerte humana, conocida, propia, hacia el final del poema parece fundirse con el yo lírico ejerciendo un cambio en él: “y siento que las letras desiguales / que escribo ahora / más pequeñas, más trémulas, más débiles, / ya no son de mi mano solamente" (vv. 45-48). Fundamental es notar este cambio en la identificación del personaje con otro así como la ausencia de dolor. Si antes buscaba al otro indefinido o se embarcaba a un viaje dentro de sí mismo, con este poema lleva la declaración a un plano superior; es decir, el poeta acepta abiertamente que ese otro que lo completa es la muerte, con lo que refuerza su tesis inicial en la que esa muerte no es algo lejano sino propio, tan suyo que se confunde consigo mismo. El final de este poema no implica una cancelación del sujeto, la muerte no es superior ni ha llegado para acabar la vida, sino que para Villaurrutia su invocación es, como también lo era para los románticos, una invocación a la vida. 
Esta muerte también es cosa, también es lugar. La manera en que se describe a la muerte en "Nocturno de la alcoba" es como un espacio, pero recuerda igualmente una presencia que ha existido desde siempre: "la muerte toma siempre la forma / de la alcoba que nos contiene" (vv. 1-2). Pero este poema deja ver un atisbo de la inmanencia del poeta hacia ella: "es dura en el espejo y tensa y congelada" (v. 5); es decir, el rostro de la muerte está captado desde la forma del poeta que se mira en el espejo y se reconoce en él, es nítida y firme. La muerte amiga es también el otro, "el hueco que dejas en el lecho" (v. 12), "es tu palabra trunca, tus gemidos ajenos" (v. 25). La muerte es total, al mismo tiempo real y humana, como onírica y abstracta. El poeta sabe que esta muerte es el todo / nada, cosas que se pueden decir y cosas que se deben callar.

Con la peculiar presencia de la muerte se dibuja el contenido de la paradoja del miedo en Villaurrutia. Recordemos "la duda de ser y no ser realidad" (v. 20). Ahora bien, sabemos que ante un sueño es necesario despertar y al hacerlo llegaría una angustia que se correspondería con el verso de Bécquer citado anteriormente. Pero hay aquí otra paradoja cuando el poeta afirma: "Dos temas son particularmente interesantes para mí: la muerte y la angustia. La angustia del hombre ante la nada, una angustia que da una peculiar serenidad" (Villaurrutia, 1966a: 18-19). Esta paradoja está muy ligada a la del binomio fundamental de este análisis en torno a su poética. Villaurrutia escribe también sobre el dolor de: "no ser sino la estatua que despierta / en la alcoba de un mundo en el que todo ha muerto" (v. 38), donde podemos rastrear un despertar angustioso que al mismo tiempo puede ser sereno. De hecho este último verso tiende un puente perfecto hacia la conclusión sobre el manejo del sueño y la muerte. Cabe resaltar que el dolor del que habla es "inesperado" pero el énfasis del poema está en unos versos antes: 
Abre mis ojos donde la sombra es más dura

y más clara y más luz que la luz misma

y resucita en mí lo que no ha sido. (vv. 33-35)

El despertar es oscuro pero también es luminoso y le sucede una resurrección. Extraño resultaría que dentro de una obra en que habita la oscuridad y la muerte existan múltiples menciones a lo abierto, a la luz y a la vida. Alí Chumacero escribió que en Nostalgia de la muerte: "la emoción, vínculo inmediato con el mundo, se convierte ahí en ideas que, acariciadas por el verso y volcadas en palabras, llegan a construir el poema" (1966b: 15). Siguiendo esta afirmación habría que detenernos a reflexionar sobre la visión de la existencia que Villaurrutia refleja en este poemario, lo que lo transporta directamente a la emoción central de la que habla Chumacero. Dicha emoción es en realidad la vida, la luminosidad de la misma.

La respuesta de su visión existencial se encuentra escondida en el carácter engañoso del título del poemario. Con tantas menciones a la muerte, y por las diversas formas en que aparece, podría pensarse que se trata de la nostalgia que siente la muerte, como personificación; sin embargo, no hay que olvidar que en realidad el poemario se trata siempre del yo lírico y la nostalgia que éste siente por la muerte. Esto se explica en el poema "Paradoja del miedo" donde el poeta se afirma como un ser para la muerte y donde explica que el miedo mayor no es a la muerte en sí, sino a la falta de reconocimiento y pérdida de la identidad propia:

El miedo de dejar de ser uno mismo

ya para siempre,

ahogándose en un mundo

en que ya las palabras y los actos

no tengan el sentido que acostumbramos darles;

en un mundo en que nadie, 
ni nosotros mismos,

podamos reconocernos. (vv. 16-23)

Este sentimiento de confusión, inseguridad y falta de definición, supera al miedo a la muerte y explica la nostalgia. En ese caso sería más fácil temer a la muerte, que es algo fuera de uno mismo, que temerle a un yo incomprensible, a verse como un ser que no se define y al que nadie puede reconocer. Pero recordemos que la muerte en Villaurrutia no es una extraña. En el "Nocturno en que habla la muerte", vemos que cuando la muerte habla, le anuncia la imposibilidad de su propia comprensión como sujeto y ese es el verdadero temor:

Nada es la tierra que los hombres miden y por la que matan y mueren;

ni el sueño en que quisieras creer que vives sin mí cuando yo misma lo dibujo y lo borro. (vv. 23-26)

El final de "Paradoja del miedo", además, no es una oda a la muerte, sino a la vida y ahí también nos presenta el poema una suerte de paradoja: "puesto que ya no puede morir, / sólo un muerto, profunda y valerosamente, / puede disponerse a vivir" (vv. 58-60).

Antes mencioné cómo Villaurrutia sentía que la muerte la llevaba dentro, en sus palabras, era traerla "como el fruto lleva a la semilla" (Villaurrutia, 1966: 18). El despertar de la estatua está vinculado con la abstracción que hace Villaurrutia de la muerte. Octavio Paz explica que se trata de una inversión del viejo "despertar es morir" y no se equivoca: "en la vigilia, si somos lúcidos, vivimos nuestra propia muerte. El contenido de nuestra vida es nuestra muerte. Estamos habitados por ella" (Paz, 1978: 81). El sentimiento de la estatua que "despierta en la alcoba de un mundo en el que todo ha muerto" (vv. 37-38) es un sentimiento de claridad y luz, de serenidad puesto que "resucita en mí lo que no 
ha sido" (v. 35) y así funciona como demostración de la inversión sugerida por Paz en torno al antiguo tópico. Una vez más Villaurrutia demuestra sus filiaciones y predilecciones como hijo de la tradición romántica europea pues esta idea tiene raíces justo ahí, donde la vida y el sueño tienen todo en común, "sobre todo desde el romanticismo, el sueńo se ha identificado con la vida; el sueńo no es la muerte sino la otra vertiente de la vida" (Paz, 1978: 56).

En la apreciación de Xirau, Villaurrutia es un hombre que "excesivamente subjetivo para dar con símbolos universales de la muerte, vive su muerte, la hace pan de todas las noches" (2004: 169). Villaurrutia no puede, entonces, mostrarse temeroso de morir. Él mismo afirma: "La muerte no es, para mí, ni un fin, ni un puente tendido hacia otra vida, sino una constante presencia, un vivirla y palparla segundo a segundo... presencia que sorprendo en el placer y en el dolor" (1966a: 19). La muerte sería para el poeta esa mezcla de algolagnia también entre la angustia y la serenidad, y en ese umbral indefinible se encuentra él mismo, de la mano de su propia muerte, en el lugar "entre."

Así es que es sólo en ese intersticio de la indefinición logra paradójicamente definirse. Al igual que sólo en la misma paradoja del miedo a la muerte se instala en una afirmación de la vida. En el estado intermedio puede hallar su verdad y dicho estado se encuentra en el sueño. Siguiendo a Béguin, al igual que la poesía, el sueño y las revelaciones sucedidas en la indefinición tienen el precio inestimable de que "nos liberan de nuestra soledad de individuos separados, nos ponen en comunicación con esos abismos interiores que ironizan la vida de la superficie" (1992: 161).

Por eso el poeta no teme al despertar, pues se afirma desde el inicio del poema, a manera de Heidegger, como un ser para la muerte, "todo poeta descubre su filósofo y yo lo he encontrado en Heidegger” (Villaurrutia, 1966: 19). Si no hay muerte que aceche peligrosamente, no habrá más remedio que entregarse a la vida. 
Villaurrutia entiende totalmente que sólo la muerte puede afirmar la vida, así como sólo el sueńo puede afirmar la realidad predilecta y sólo dormir / morir lleva a despertar / vivir.

\section{Bibliografía}

Argullol, Rafael, 2006, La atracción del abismo, un itinerario por el paisaje romántico, Barcelona, Acantilado.

Bécquer, Gustavo Adolfo, 1976, Rimas y leyendas, México, Aguilar.

Béguin, Albert, 1992, El alma romántica y el sueño, México, FCE.

Monge, Carlos Francisco, 2001, "Entornos del surrealismo en Xavier Villaurrutia: la poesía y el ensayo", en Merlin H. Foster (comp.), Las vanguardias literarias en México y la América central. Bibliografía y antología crítica, Frankfurt am Main, pp. 277-296.

Novalis, 1985, Himnos a la noche, Rafael Argullol (trad. y notas), Barcelona, Icaria.

Quevedo y Villegas, Francisco de, 1986, "Más solitario pájaro ¡en cuál techo?”, en Poesía amorosa, México, Joan Boldó i Climent Editores.

Paz, Octavio, 1978, Xavier Villaurrutia en persona y obra, México, FCE.

Villaurrutia, Xavier, 1966a, "La poesía”, Revista de Bellas Artes, núm. 7, pp. 17-19.

, 1966b, Obras, Alí Chumacero (pról.), Miguel Capistrán, Alí Chumacero y Luis Mario Schneider (recop.), Luis Mario Schneider (biblio.), México, FCE.

Xirau, Ramón, 2004, "Xavier Villaurrutia: presencia de una ausencia”, en Entre la poesía y el conocimiento. Antología de ensayos criticos sobre poetas y poesía iberoamericanos, México, FCE, pp. $161-171$ 